\title{
A magia do vestibular: a produção da crença no "dom" entre os estudantes do IFSP
}

The magic of the admission test: the production of belief in "gift" among the students of the IFSP

\author{
Nicolau Dela Bandera*
}

Universidade de São Paulo

Resumo Este artigo analisa os efeitos subjetivos e simbólicos produzidos entre os estudantes aprovados por um dos vestibulares mais concorridos na cidade de São Paulo, o vestibulinho para acesso ao ensino médio da Escola Técnica Federal. Um dos efeitos do vestibular, definido por Pierre Bourdieu (2008) enquanto um rito de instituição, refere-se à produção de um sentimento de eleição que confirma a crença no "dom" e legitima desigualdades sociais. Os estudantes aprovados pelo vestibulinho da Federal cultivaram uma autoimagem como membros de um grupo de excelência, com um "carisma grupal" alicerçado no mérito escolar. A pesquisa possui como metodologia a realização e análise de entrevistas semiestruturadas com 21 jovens, selecionados a partir de um questionário aplicado a todos os estudantes do terceiro ano do ensino médio (total de 257 questionários).

PALAVRAS-CHAVE: Vestibular; Ensino médio; Desigualdades sociais; IFSP.

\begin{abstract}
This paper analyses the subjective and symbolic effects produced among the admitted students by one of the most competitive admission test in São Paulo: the vestibulinho for accessing to Escola Técnica Federal. One of the vestibulinho effects, defined by Pierre Bourdieu as a rite of institution refers to the production of a sense of election that confirms the belief in the "gift" and justifies social inequalities. The students selected by the admission test of Federal cultivated a self-image as members of a group of excellence, with a "group charisma" grounded in the academic merit. The research methodology consists of 21 semi-structured interviews with students, chosen from the results of a survey applied with all students of the third year of the school (total of 257).
\end{abstract}

KEYWORDS: Admission test; High school; Social inequalities; IFSP. 


\section{Introdução}

Os vestibulares, sobretudo os exames de acesso ao ensino superior, têm sido examinados pela literatura sociológica brasileira a partir dos efeitos produzidos na reprodução das desigualdades culturais, étnicas e econômicas (NOGUEIRA, 2003; W. ALMEIDA, 2009). Na maioria desses estudos, o objetivo volta-se para a investigação da relação entre estratificação social e o papel da educação em sua reprodução. Algumas pesquisas recentes (A. ALMEIDA, 2009; W. ALMEIDA, 2009), contudo, têm incorporado uma dimensão fundamental para o estudo dos vestibulares e da relação entre escola e classes sociais: os efeitos subjetivos e simbólicos que os exames tendem a produzir nos estudantes que foram (ou não) aprovados. Não deixando de lado a análise dos efeitos objetivos produzidos por esses exames na reprodução das desigualdades estruturais na sociedade brasileira, tais estudos lançam luz para a produção da crença no próprio privilégio, justificado pelos próprios agentes por ser visto como fruto do "talento", do "esforço" e das "realizações pessoais". Neste artigo, apresento uma contribuição específica a essa literatura, estudando os efeitos subjetivos e simbólicos produzidos entre os estudantes aprovados em um dos vestibulares mais concorridos na cidade de São Paulo, o vestibulinho para acesso ao ensino médio da Escola Técnica Federal ${ }^{1}$. Se há diversos estudos sobre a (re)produção das desigualdades pelos exames de acesso ao ensino superior, as desigualdades no acesso ao ensino médio só recentemente passaram a chamar a atenção dos estudos sociológicos (A. ALMEIDA, 2009). Neste artigo, serão analisados os efeitos produzidos pelo vestibulinho tanto nas representações subjetivas dos estudantes acerca de si mesmos quanto em relação ao perfil da instituição, vista como uma escola de ensino médio com "ares de universidade".

Os exames exercem uma função mágica ao estabelecer fronteiras simbólicas entre as pessoas. Segundo Bourdieu (2008, p. 102), os vestibulares produzem uma alquimia social que está na base da formação das classes dominantes. Eles produzem a crença coletiva de que o privilégio é o resultado meritório da "inteligência" e do "dom". Neste artigo, investigarei em que medida essa mágica é operada pelo vestibulinho da Federal, produzindo um sentimento particular de eleição entre os jovens que os impulsiona nas disputas escolares e justifica as desigualdades no sistema de ensino. O ensino médio é um momento da trajetória escolar privilegiado para o estudo da produção social da crença no "dom" e no "mérito", pois é nesse nível de ensino que os jovens criam representações sobre si mesmos, o mundo e o futuro ("sou inteligente? Sou capaz de passar no vestibular?"), que significam o destino deles rumo às instituições de ensino superior.

A pesquisa possui como metodologia a realização e análise de entrevistas semiestruturadas com 21 jovens, selecionados a partir de um questionário aplicado a todos os estudantes do terceiro ano do ensino médio do colégio em 2009 (total de 257 questionários). O critério adotado para a seleção dos entrevistados respeitou a heterogeneidade social interna das turmas de ensino médio. Nos resultados do questionário, aplicado entre os estudantes do terceiro ano da Federal, pode-se observar que a grande maioria dos ingressantes em 2009 estudou em colégios particulares no ensino fundamental (78\%), ainda que exista uma pequena proporção de estudantes oriundos de escolas públicas (18\%) e de outros que estudaram tanto em escolas públicas quanto 
particulares $(4 \%)^{2}$. O corpo discente é formado majoritariamente por meninos (71\%), estudantes autoclassificados como brancos (69\%), uma parcela significativa de estudantes autoclassificados como amarelos (17\%) e uma minoria de estudantes negros $(14 \%)^{3}$. Com o intuito de representar tais diferenças entre os jovens do ensino médio da Federal, selecionei para as entrevistas 21 estudantes com as seguintes características: 14 meninos e 7 meninas; 14 estudantes autoclassificados como brancos, 5 autoclassificados como amarelos e 2 estudantes negros; 15 estudantes provenientes de colégios particulares e 6 oriundos de escolas públicas de ensino fundamental. As entrevistas (com duração de uma a duas horas) ocorreram no próprio colégio ou na biblioteca do Centro Cultural São Paulo e abordaram a história familiar, a trajetória escolar dos jovens e as representações deles sobre a escola e o próprio futuro. Neste artigo, analisarei em profundidade o resultado das entrevistas com cinco jovens, cujas narrativas são representativas das demais. Contudo, a referência a outras entrevistas será realizada quando pertinente, inclusive para informar ao leitor as possibilidades e os limites de certas generalizações. Após a transcrição e sistematização dos resultados, selecionei as narrativas dos jovens sobre os vestibulares e os efeitos dos exames nas representações realizadas por eles sobre si mesmos e o colégio.

\section{A produção da crença no "mérito" e no "talento"}

Nas 21 entrevistas realizadas, os estudantes aprovados no vestibulinho da Federal produziram uma autoimagem - "os estudantes da Federal" - como membros de um grupo de excelência, com um "carisma grupal” (ELIAS; SCOTSON, 2000) alicerçado no mérito escolar. Graças às conquistas específicas no jogo escolar obtidas por esses estudantes, eles criam uma identidade, individual e coletiva, como membros de um grupo carismático, portador de virtudes que outros grupos, estudantes de outras escolas e até mesmo os estudantes matriculados nos cursos técnicos ou no ensino superior da própria Federal (com vestibulares menos concorridos que o curso de ensino médio), não têm. Um dos efeitos do vestibulinho refere-se a esse sentimento de eleição, que serve tanto para confirmar a crença no "dom" entre os estudantes como para justificar as desigualdades no sistema de ensino.

$\mathrm{Na}$ entrevista com Rosa ${ }^{5}$, estudante oriunda de uma escola particular de ensino fundamental que se autoclassifica como nipo-brasileira, podemos observar essa construção da imagem dos estudantes do ensino médio enquanto um grupo de excelência a partir do contraponto em relação aos jovens da escola matriculados no ensino técnico ou no superior e que passaram por processos seletivos menos concorridos. A diferença entre os dois grupos de estudantes no interior da mesma escola é vista por Rosa como algo etéreo e que está no ar cultural do colégio, algo difícil de definir e, de fato, algo que não se pode definir, pois trata-se aqui de uma diferença de habitus e de disposições incorporadas que tendem a ser vistas pelos agentes como naturais (BOURDIEU, 2007). A estudante diz que se sente em extinção justamente por causa da mudança que ocorreu no colégio com o progressivo fechamento das turmas de ensino médio e o aumento do número das turmas do ensino técnico e superior no final da década de 2000 . 
Rosa: Quando a gente entrou, tinha muita coisa cultural, principalmente organizada por parte dos estudantes. Agora é diferente. A gente sentia que o clima dos mais velhos era uma coisa muito diferente, porque vira e mexe você saía e encontrava uma banda tocando no pátio. Tinha alguém tocando saxofone no meio do corredor. Você sentia um ar diferente. Agora é menos. Não sei se por causa do tipo de curso que é diferente. Porque agora está acabando o ensino médio; está mais técnico-profissionalizante. A gente não sente mais esse clima de leveza no ar, um ar diferente.

Entrevistador: Por quê?

Rosa: A atmosfera é diferente. Existe esse preconceito, não sou só eu. Você percebe a diferença do conhecimento que o pessoal do ensino superior tem, o tipo de ambiente que eles vivem, e o que a gente convive. Tanto que no ensino médio a maioria vem de escola particular. No superior é gente que está trabalhando, que tem outra mentalidade. E como é menos concorrido o vestibular, é mais fácil de entrar. A gente se sente meio em extinção.

Neste curto trecho de entrevista, a estudante utiliza em diversas oportunidades o adjetivo diferente, no sentido de distinto, para tentar designar a mudança. Rosa também enfatiza que não se trata apenas de um preconceito individual: "existe esse preconceito, não sou só eu”. Há, portanto, um trabalho coletivo de produção de categorias para interpretar a mudança no público da instituição e para designar a diferença cultural e de classe dos estudantes do ensino médio, provenientes, em sua maioria, de escolas particulares de ensino fundamental, que passaram por um vestibulinho extremamente concorrido.

Os estudantes entrevistados da Federal também fortalecem a crença no próprio "dom" ao prestar diversos tipos de vestibular. Observa-se entre alguns entrevistados, por exemplo, o fato de estudantes que querem cursar Medicina, e não se sentem preparados para passar no vestibular extremamente concorrido para essa carreira, prestam, durante o segundo ano do ensino médio, provas para cursos menos concorridos para adquirir experiência. Algo que pode parecer sem sentido à primeira vista, possui sua razão sociológica de ser: o exame como treineiro fortalece a crença desses jovens no jogo escolar.

Vejamos como Bruno, estudante autoclassificado como branco e oriundo de uma escola particular de ensino fundamental, descreve sua experiência como treineiro no segundo ano do ensino médio da Federal:

Bruno: Eu sempre pensei em Medicina, Medicina, Medicina. Só que aí, no segundo ano do ensino médio, como treineiro do vestibular, mais vale você pegar aquelas carreiras menos concorridas e prestar. Então eu achei uma carreira lá legal, Gerontologia [na USP-Leste]. Fiz a primeira fase da Fuvest, passei para a segunda. Eu passei em segundo lugar de Gerontologia, como treineiro. Não era o que eu tinha interesse, e por mais que eu quisesse, eu estava no segundo ano e não poderia fazer o curso antes de terminar o ensino médio. Mas eu fiquei feliz pra caramba por ter passado em segundo lugar como treineiro. 
Os jovens estudantes da Federal procuram experimentar o êxito escolar por meio dos vestibulares, acostumando-se às conquistas. Trata-se aqui de experiências excitantes que os jovens vivenciam nesses constantes exames, o que impulsiona a gana - a libido, nos termos de Bourdieu (2001) - por novas conquistas no jogo escolar. Nogueira (2003, p. 135), pesquisando os efeitos do "treineiro" entre os estudantes de um colégio federal em Belo Horizonte, também reforça o argumento de que tais exames e "simulações" não produzem apenas efeitos cognitivos, o aprendizado do savoir faire das provas, como também efeitos no plano emocional, tranquilizando os estudantes, principalmente aqueles que se sentem mais inseguros.

Essas experiências também afastam o sentimento de culpa que poderia ser produzido em tais situações - e que em algumas entrevistas aparece principalmente entre os estudantes oriundos de escolas públicas no ensino fundamental -, característico de indivíduos em ascensão social que não se sentem à altura do que conquistam e passam a pensar naqueles que abandonaram o jogo escolar ou, como é mais frequente atualmente, naqueles que permaneceram nas instituições precárias do ensino público, os "excluídos do interior" (BOURDIEU; CHAMPAGNE, 1998; W. ALMEIDA, 2009). O envolvimento no jogo escolar implica, portanto, o esquecimento daqueles que ficaram para trás, ou nem conseguiram entrar seriamente no jogo. Os vestibulares auxiliam na produção desse esquecimento, naturalizando as desigualdades culturais e sociais.

Existem outros tipos de emulações, menos explícitas que os vestibulares, que também produzem e reforçam esse sentimento de eleição. Alguns dos entrevistados afirmaram que desde o início de sua escolarização são vistos como os "melhores estudantes" nas escolas em que estudaram. Seja porque eles entraram na escola já sabendo ler, seja porque possuíam um desempenho acima da média no início de sua escolarização, alguns desses jovens foram rotulados desde cedo como "excepcionais", "melhores", "dotados", "excelente", "hiperativo muito inteligente". Esses elogios e categorias de julgamento por parte dos professores, baseados, sobretudo, nos resultados de exames e provas, tendem a produzir uma autoimagem dos estudantes alicerçada nos valores escolares. Eles são valorizados e se valorizam pelas conquistas escolares que obtiveram, sendo, por isso mesmo, mais crentes e devotos à escola. Ronaldo, por exemplo, é visto na escola como "o prodígio", justamente por ter sido aprovado em terceiro lugar no vestibulinho da Federal com apenas 13 anos, quando a maioria dos demais ingressa no colégio com 14 ou 15 anos. O vestibulinho para acesso à escola consagra, portanto, a imagem do estudante como "excepcional". A precocidade ainda faz com que seus bons resultados escolares não sejam vistos como frutos de um trabalho árduo de aquisição de capital cultural que consome todo seu tempo; eles são antes vistos como a manifestação da "inteligência" e do "dom".

Alex, estudante autoclassificado como negro, oriundo de uma escola pública de ensino fundamental, realiza uma comparação entre a competição no esporte e na educação: 
Entrevistador: Você se cobra bastante? Você exige bastante de você mesmo?

Alex: Eu sou bastante exigente, tanto no estudo, quanto no esporte. Eu sempre entro no jogo para ganhar, se eu não jogo bem eu fico bravo comigo e brigo com todo mundo.

Alex afirma, por meio dessa analogia, que o estudo é um espaço de competição em que a gana de vencer também se faz presente. Estar entre os primeiros nos exames e vestibulares, para alguns estudantes do colégio, os autodenominados "nerds", é uma questão essencial; para outros, como o "prodígio", o que importa não são os prêmios que a escola atribui imediatamente (os elogios do professor, as médias das notas), por vezes recusados, principalmente pelos meninos, por ser algo visto como muito escolar e feminino, mas o que está em jogo na competição escolar fora da escola, que é o vestibular. Por um lado, estar entre os primeiros na escola pode ser algo até vexatório - ainda que na Federal não seja um estigma, como acontece com meninos muito estudiosos em outros colégios públicos de São Paulo, que têm sua masculinidade colocada em questão por serem vistos como dóceis às regras escolares, principalmente nas séries iniciais do ensino fundamental (CARVALHO, 2008). Por outro lado, estar entre os primeiros do vestibular, tanto no exame para ingresso no colégio quanto nos vestibulares para acesso às universidades públicas, é um motivo de orgulho e de reconhecimento pelos demais. Trata-se aqui de uma pessoa que venceu as batalhas grandiosas do jogo escolar, e não as pequenas da rotina escolar. $\mathrm{O}$ caráter extraordinário da conquista - mais evidente no caso do prodígio que foi aprovado com 13 anos e em terceiro lugar no vestibulinho da escola - reforça a crença no "dom", produzindo o carisma alicerçado no "mérito" que forma a autoimagem desses jovens. Não por acaso, os estudantes realizam constantes comparações entre si, para ver quem ficou colocado em uma melhor posição nos simulados e vestibulares. Helena, estudante autoclassificada como branca e proveniente de uma escola particular de ensino fundamental, compara o seu resultado no exame de treineiro da Fuvest (vestibular para ingresso na USP)com o de Marcos, o "melhor estudante" da classe:

Helena: Eu fiz de treineiro a Fuvest no ano passado. Eu passei. Teve a colocação para humanas. O Marcos ficou em décimo; eu, em décima primeira. Eu acho que ele ficou bravo com isso. Eu não acreditei quando eu vi o resultado.

Essa valorização da competição escolar produz também uma aceitação entre esses estudantes da meritocracia. Em algumas discussões no colégio sobre a política de cotas do Governo Federal, a crença no mérito, elemento essencial na composição da identidade dos estudantes, foi defendida com muito ardor. Poucos jovens cederam ante o argumento de que uma instituição pública, como a Federal, deveria atender, prioritariamente, estudantes oriundos de colégios públicos durante o ensino fundamental, e não aqueles que estudaram em colégios particulares. Sendo a maioria deles proveniente do setor privado, a afirmação de que uma minoria de estudantes das escolas públicas conseguiu entrar no colégio, recorrendo unicamente ao seu "esforço", repõe o mito liberal da mobilidade social pelo mérito intelectual (MACLEOD, 1995), particularmente forte entre eles. 
$\mathrm{Na}$ entrevista com Rosa, por exemplo, podemos ver de maneira mais clara como essa crença no mérito e no individualismo se manifesta. Tal crença é particularmente forte entre os estudantes tidos como mais estudiosos e dedicados, por vezes reconhecidos pelos outros e por si mesmos como "nerds":

Rosa: Entre a gente tem aqueles que são mais estudiosos, não fechados, mas mais estudiosos, que levam mais a sério. Eu me colocaria nesse grupo; mas não que eu não converse com outras pessoas. Eu sou contra você se dedicar e alguém se aproveitar, puxar do seu esforço para se aproveitar de você e depois se dar melhor. $O$ esforço pessoal deve ser valorizado.

O individualismo, como crença e prática social (VELHO, 1987), surge, portanto, como um dos elementos que compõem a identidade e o ethos de alguns desses jovens que passaram, ao longo de suas vidas, por sucessivos exames e avaliações.

\section{"Um colégio com ares de universidade"}

O vestibulinho também influencia a imagem que os estudantes possuem da Federal, que é vista por eles como "um colégio com ares de universidade". A illusio, ou seja, a crença de que vale a pena se envolver no jogo escolar (BOURDIEU, 2001, p. 199-203), é tão incorporada por esses jovens que a Federal pode ser menos coerciva e disciplinar do que a maioria das outras instituições escolares. Segundo os estudantes, há um "clima de liberdade" que predomina na escola, que "os prepara para o que vão encontrar na universidade" e que os amadurece.

Alex: É que aqui [na Federal] é bem diferente dos colégios particulares. Dá uma boa base para a universidade. Aqui você tem que ser meio autodidata, estudar por conta própria, não é que nem em um colégio particular que os professores dão a matéria de mão beijada, e falam o que vai cair na prova. Aqui o professor te dá a base, e se você quiser saber mais, tem que se virar. Na minha antiga escola, você era meio que obrigado a estudar. Aqui você tem muita liberdade, você pode sair a qualquer hora, entrar a hora que quiser. Aqui tem que ter vontade.

Em todas as 21 entrevistas, tanto os estudantes provenientes de colégios públicos quanto os de colégios particulares afirmaram que a Federal se diferencia de seus antigos colégios principalmente por seu laxismo pedagógico. Os colégios particulares são descritos como espaços estritamente disciplinares, em que os professores, os inspetores e as freiras - no caso dos colégios católicos - controlam tudo o que os estudantes fazem ou deixam de fazer, como, por exemplo, o uso estrito do uniforme escolar e a circulação no espaço escolar. Na Federal, apesar de haver uniforme, os estudantes não o utilizam, pois não há "fiscalização" por parte dos inspetores. No pátio é possível encontrar muitos estudantes com camisetas de bandas de rock e de times de futebol. Os estudantes da Federal têm liberdade para circular por todo o espaço da escola - razoavelmente diversificado e amplo -, podendo frequentar as quadras, a biblioteca, o pátio ou o bosque durante o horário das aulas. Os professores e os inspetores não controlam estritamente o horário de entrada e saída. Por exemplo, se o estudante quiser, ele pode chegar para a terceira aula, realizar uma prova e ir embora logo em seguida. 
No terceiro ano do ensino médio, esse laxismo é ainda mais acentuado. Pelo fato de muitos alunos estudarem em cursinhos pré-vestibulares, a atenção deles desprende-se do colégio e volta-se para o vestibular. Enquanto os colégios particulares intensificam seu trabalho escolar no último ano do ensino médio (A. ALMEIDA, 2009), a Federal pode "se dar ao luxo", nas palavras da professora Paula, de "largá-los, pegar mais leve com eles no último ano, pois os professores sabem que eles vão ter um vestibular pela frente".

Essa realidade só é possível, sem prejudicar os resultados escolares, quando existe disposição para o estudo e a autodisciplina, particularmente forte nesses estudantes, oriundos de frações das classes médias que dependem da escola para sua estabilidade ou ascensão social. Nas palavras de Alex, citado acima, "aqui tem que ter vontade". Os estudantes trazem incorporada a responsabilidade e o autocontrole, não necessitando que alguém exerça uma coerção externa e que uma autoridade negocie e afirme a todo o momento as regras e o sentido do jogo. A coerção é altamente interiorizada; a socialização fez com que cada um adquirisse um autocontrole e uma disciplina que são fundamentais nos combates específicos do jogo escolar e, em um nível mais abrangente, na luta de classes pela classificação social, como reconhecido por Roberto, estudante do terceiro ano, quando compara a autonomia e autodidaxia cultivadas na Federal com o novo ethos adotado pelas empresas (BOLTANSKI; CHIAPELLO, 2009), que valoriza a flexibilidade e a responsabilização do trabalhador: "As empresas estão adotando esse recurso à liberdade. Elas descobriram que você tem maior produtividade quando você deixa as pessoas fazerem do jeito que elas querem".

Bianca, estudante autoclassificada como branca e oriunda de um colégio particular de ensino fundamental, afirmou que o estilo da Federal - um colégio não disciplinador - só é bem sucedido por causa da seleção dos estudantes que são, desde o princípio, crentes no jogo escolar, dispostos a estudar e, principalmente, sem maiores dificuldades para aprender em função da herança cultural que obtiveram e do capital escolar que acumularam em sua trajetória social e escolar:

Bianca: A Federal é um ótimo colégio acima de tudo porque tem estudantes pré-selecionados. O ensino da Federal para estudantes da escola pública não ia mudar em nada, seria um ensino qualquer. A gente tem professores bons se você está disposto a estudar. E geralmente os estudantes da Federal estão predispostos a estudar, eles passaram pelo vestibulinho, estudaram em escola particular. Se não estão predispostos a estudar, se não se esforçam tanto, são estudantes que têm facilidade em aprender. Não tem aquele cara que você diz: “Não tem jeito!".

Bianca possui um acúmulo de capital cultural sem igual na Federal - seu avô é professor universitário -, o que lhe possibilita certo distanciamento da adesão quase encantada produzida pelo vestibulinho e encontrada entre os demais estudantes em relação ao estilo do colégio. Outra diferença em relação à maioria dos colégios particulares - essa menos enunciada pelos estudantes - é o fato da Federal ser menos pautada diretamente pela urgência do vestibular, o que a aproxima da posição ocupada no espaço das instituições escolares pelos colégios particulares frequentados pelas frações mais tradicionais das classes dominantes, com alto capital cultural e que não 
esperam que a escola ofereça somente uma formação para o vestibular (A. ALMEIDA, 2009). Na Federal, os professores dizem que o ensino visa a "formação para a vida" e não somente a formação instrumental com o objetivo de passar no vestibular. Os estudantes encontram essa formação mais direcionada para o vestibular nos cursinhos frequentados no terceiro ano do ensino médio.

Como o colégio não controla estritamente a presença dos estudantes, nem possui um ensino pautado por apostilas ou livros didáticos, os estudantes precisam desenvolver uma disposição para a autonomia no estudo e a produção do próprio material didático, por meio da consulta à biblioteca da escola e às bibliotecas públicas da cidade, adquirindo precocemente disposições características do que Coulon (2008) denominou de "ofício de estudante". Na Federal, além disso, ocorre um processo de amadurecimento no sentido de que os pais já não possuem acesso privilegiado ao colégio. Os estudantes precisam resolver sozinhos os próprios problemas burocráticos e institucionais, tais como a realização das matrículas, mudança de turma, negociação com professores e diretores quanto a questões disciplinares. Trata-se aqui de um processo de filiação institucional similar àquele pesquisado por Coulon (2008), no qual os estudantes aprendem praticamente como lidar com as injunções burocráticas da instituição. Novamente na entrevista com Bianca podemos constatar essa diferença da Federal em relação ao colégio particular:

Entrevistador: Qual a diferença de clima entre os dois colégios, os ares da Federal e desse colégio? Como você sentiu?

Bianca: Foi muito impactante, porque o Pathernon era muito perto da minha casa, minha mãe tinha amizade com a diretora, a coordenadora.

Entrevistador: Era família.

Bianca: Sim, minha família estava dentro do colégio. Tinha aquilo de qualquer coisa que acontecesse chamar os pais, ligar para a família. Era horrível. Se você brigasse na escola, aí eles ligavam para falar que brigou. Você não brigava nem de bater, mas de bate-boca, era um saco. Eu estava louca para me ver livre dessas coisas. Então, eu queria novos ares.

Entrevistador: Na Federal, o que você encontrou?

Bianca: Eu encontrei essa liberdade. Isso é fato. Minha mãe às vezes me buscava depois do trabalho. E essa era a máxima relação dela com a escola. Ela não entrava lá dentro, não pode. Minha mãe e eu não temos contato com a direção. Até hoje eu não sei qual é a cara do meu diretor. Isso foi muito chocante.

Nas entrevistas aparece também outra forma de expressar como a Federal suscita um amadurecimento dos estudantes, possibilitando-lhes relativa emancipação de uma infância superprotegida: o fato deles aprenderem a andar de ônibus e metrô pela cidade de São Paulo. A maioria dos jovens apresenta, nas entrevistas, o fato de "pegar ônibus e metrô" como uma das maiores diferenças da Federal. É essa experiência que, por vezes, eles entendem como "a formação para a vida" que a Federal oferece, 
em um sentido distinto daquele atribuído a essa expressão pelos professores. A escola permite a eles um distanciamento relativo do universo restrito e protegido da família, expresso também na citação anterior de Bianca, ao se distanciar do colégio onde todos conheciam seus pais.

\section{Conclusão}

O vestibular é uma competição em que aqueles com alto capital escolar e com a illusio produzida pelos próprios exames se entregam de corpo e alma. Como vimos nos itens anteriores deste artigo, na escola, como no esporte, o importante para os jovens estudantes da Federal não é só competir, mas ganhar. A illusio no jogo escolar implica, portanto, uma libido específica para disputar aquilo que está em jogo na escola ou fora dela, uma satisfação emocional pelas conquistas escolares que para pessoas com outras disposições não faz sentido ou não é a conquista essencial da vida.

Um efeito menos evidente do vestibulinho, que reforça o efeito estrutural da reprodução das desigualdades sociais, refere-se à magia da instituição, analisada por Bourdieu no livro La noblesse d'État (1989), que joga água no moinho de produção da crença na "meritocracia e no dom" entre esses jovens, dispostos a constantes superações de si para provar aos outros e a si mesmos que merecem ser quem são. Ao serem aprovados em um vestibular altamente concorrido, esses jovens não ganham apenas recursos objetivos, como o capital escolar; eles adquirem também recursos simbólicos necessários para justificar para si mesmos e para os outros o privilégio que possuem como fruto de seu próprio "esforço" e "inteligência" (KHAN, 2011).

$\mathrm{O}$ vestibulinho, enquanto um rito de instituição, transforma diferenças de fato, produzidas socialmente, em distinções legítimas ou diferenças de direito, socialmente conhecidas e reconhecidas (BOURDIEU, 1989). É essa a magia social que o sistema de ensino de nível médio de São Paulo, extremamente hierarquizado, inclusive no setor público - e não somente na separação entre setor público e setor privado -, tende a produzir, separando os eleitos e oferecendo a eles uma educação de melhor qualidade em uma instituição como a Federal, localizada no topo das instituições públicas de ensino médio. Vimos, ainda, que a Federal podia ser uma escola "com ares de universidade”, concedendo maior autonomia aos estudantes, em função desse público altamente selecionado. Com o fim das turmas exclusivas de ensino médio e a expansão para os campi no interior do estado, o perfil da instituição mudou radicalmente na última década. Resta saber se essas mudanças implicaram ou não em uma democratização no acesso, mas esta já se constitui como outra pesquisa, que foge do escopo deste artigo.

\section{Referências}

ALMEIDA, A. M. F. As escolas dos dirigentes paulistas. Ensino médio, vestibular, desigualdade social. Belo Horizonte: Argvmentvm, 2009.

ALMEIDA, W. M. de. USP para todos? Estudantes com desvantagens socieconômicas e educacionais e fruição da universidade pública. São Paulo: Musa, 2009.

BOLTANSKI, L.; CHIAPELLO, E. O novo espírito do capitalismo. Tradução de Ivone Benedetti. São Paulo: Martins Fontes, 2009. 
BOURDIEU, P.; CHAMPAGNE, P. Os excluídos do interior. In: NOGUEIRA, M. A.; CATANI, A. (Orgs.). Pierre Bourdieu: Escritos de educação. Petrópolis: Vozes, 1998, p. 217-227. BOURDIEU, P. La Noblesse d'État. Paris: Ed. de Minuit, 1989.

. Meditações Pascalianas. Tradução de Sergio Miceli. São Paulo: Bertrand Brasil, 2001.

. A distinção: crítica social do julgamento. Tradução de Daniela Kern e Guilherme Teixeira. São Paulo/Porto Alegre: Edusp/Zouk, 2007.

A economia das trocas linguísticas. Vários tradutores. São Paulo: Edusp, 2008.

CARVALHO, M. P. Gênero na sala de aula: a questão do desempenho escolar. In: MOREIRA, A.F.; CANDAU, V.M. (Orgs.). Multiculturalismo: diferenças culturais e práticas pedagógicas. Petrópolis: Vozes, 2008, p. 90-124.

COULON, A. A condição de estudante: a entrada na vida universitária. Tradução de Georgina Santos e Sônia Sampaio. Salvador: EDUFBA, 2008.

D’ANGELO, M. Escola técnica Federal de São Paulo. A integração do saber e do fazer na formação de nível médio. 300f. Tese (Doutorado em História). São Paulo, Faculdade de Filosofia, Letras e Ciências Humanas, Universidade de São Paulo, 2007.

ELIAS, N.; SCOTSON, J. L. Os estabelecidos e os outsiders: sociologia das relações de poder a partir de uma pequena comunidade. Tradução de Vera Ribeiro e Pedro Sussekind. Rio de Janeiro: Jorge Zahar, 2000.

HASENBALG, C.; SILVA, N. V. Raça e oportunidades educacionais. Cadernos de Pesquisa. São Paulo, n. 73, p. 5-12, maio, 1990.

KHAN, S. Privilege. The making of an adolescent elite at St. Paul's School. Princeton e Oxford: Princeton University Press, 2011.

MACLEOD, J. Ain't no makin' it. Aspirations \& attainment in a low-income neighborhood. San Francisco e Oxford: Westview Press, 1995.

MILLS, C. W. A nova classe média. Rio de Janeiro, Zahar, 1979.

NOGUEIRA, M. A. A construção da excelência escolar: um estudo de trajetórias feito com estudantes universitários provenientes das camadas médias intelectualizadas. In: NOGUEIRA, M. A.; ROMANELLI, G.; ZAGO, N. (Orgs.). Família e escola: trajetórias de escolarização em camadas médias e populares. Petrópolis: Vozes, 2003, p. 125-154.

VELHO, G. Individualismo e cultura: notas para uma antropologia das sociedades contemporâneas. Rio de Janeiro: Jorge Zahar, 1987.

\section{Notas}

\footnotetext{
${ }^{1}$ Em 2009, os estudantes que entraram no ensino médio da Federal enfrentaram uma concorrência de trinta candidatos por vaga (por volta de 7.200 candidatos para 240 vagas). Encontramos as três denominações institucionais das últimas décadas ainda inscritas na portaria do campus da cidade de São Paulo: Escola Técnica Federal, CEFET-SP (Centro Federal de Educação Tecnológica de São Paulo) e IFSP (Instituto Federal de Educação, Ciência e Tecnologia de São Paulo). Optei, neste artigo, por empregar a designação utilizada pelos estudantes do ensino médio para se referir à escola, a "Federal". Para maiores detalhes sobre as transformações institucionais pelas quais a escola passou nas últimas duas décadas, consultar D’Angelo (2007).

${ }^{2}$ Pode-se dizer que a maioria dos estudantes do ensino médio da Federal é oriunda de famílias que pertencem a certas frações das classes médias, ocupando, principalmente, os empregos de colarinho branco descritos por Wright Mills (1979): 15,2\% dos pais dos estudantes são funcionários em posições intermedi-
} 


\section{Nicolau Dela Bandera}

árias no serviço público; $11 \%$ profissionais liberais; 9,2\% administradores de pequenas e médias empresas; 6,4\% funcionários de escritório; $6 \%$ professores do ensino médio e 7,3\% quadros técnicos. Pertencentes às frações da classe média tradicional, formada por proprietários, segundo Wright Mills (1979), e que era predominante na geração dos avós, estão: 7,8\% de pequenos comerciantes e 7,3\% de pequenos empresários. Alguns pais pertencem às classes trabalhadoras, em ocupações nos serviços urbanos desqualificados $(8,3 \%) \mathrm{e}$ industriais (5\%). Somente uma pequena minoria pertence às famílias de frações das classes dominantes, em que os pais são: 1,3\% (3 casos) militares de alta patente; $0,9 \%$ ( 2 casos) rentistas; $0,9 \%$ ( 2 casos) professores universitários; $0,5 \%$ ( 1 caso) político regional e $0,5 \%$ (1 caso) artista.

${ }^{3}$ Os estudantes autoclassificaram-se de acordo com as categorias de cor utilizadas pelo Censo: branco, amarelo, pardo, preto e indígena. Seguindo sugestão de Hasenbalg e Silva (1990), agreguei as categorias de cor pardo e preto na categoria negro.

${ }^{4}$ Os trechos entre aspas, no corpo do texto, quando não seguidos de citação, foram proferidos pelos estudantes nas entrevistas gravadas e posteriormente transcritas.

${ }^{5}$ Neste artigo utilizei nomes fictícios para designar os estudantes.

* Doutorando em Antropologia Social pela Universidade de São Paulo, São Paulo, São Paulo, Brasil.

\section{Correspondência}

Nicolau Dela Bandera - Av. 9 de julho, n. 1175, Bela Vista, São Paulo, CEP: 01313-000 - São Paulo, Brasil

E-mail: nicolaudelabandera@gmail.com

Recebido em 03 de março de 2015

Aprovado em 04 de maio de 2015 